\title{
Effect a Chemical Treatment of Pineapple Leaf Fiber (PALF) for Mechanical Properties as a Reinforced Composite Matrix Polyesters
}

\author{
Fadil Azhar Ekoputra ${ }^{1, a)}$, Sulistijono ${ }^{2}$, Ika Ismail ${ }^{3}$ \\ Material and Metallurgical Engineering, Institut Teknologi Kalimantan, Soekarno-Hatta KM. 15 Balikpapan Utara, \\ Balikpapan 76127, Indonesia \\ a) fadil3105@gmail.com
}

\begin{abstract}
Application of composite materials as a alternative materials is developed, The most of composite material is polymer matrix composite (PMC), with the polymer as a matrix and the sintetic fiber such as fiberglass and fiber carbon as a reinforced, it can make a materials with intermediete mechanical properties such as strength, hardness and thoughness, between matrix and fiber. Since the synthetic fiber was dangerous for human, so recenly developing natural fiber composite with advantages of natural fiber is more environmentally friendly, and more cheap than synthetic fiber. Otherwise, natural fiber has stong enough when it use at interior automotive parts, such as dashboard. Some cars already use the natural fiber for the interior parts. The natural fiber has a big potential, especially pineapple in Indonesia, the pineapple production at East Kalimantan is 25344 tonnes in 2014. It means a lot of leaves can be used for the natural fiber. Pineapple leaf fiber (Pineapple Leaf Fiber / PALF) has a pretty good tensile strength of $126 \mathrm{MPa}$, and Young modulus of $4405 \mathrm{MPa}$ and has a cellulose content About a 70-80\% cellulose, cellulose which has a crystalline structure, so it can be good reinforced for composite. The result of this experiment, the optimum value of tensile strength is $29.9648 \mathrm{MPa}$, at composite PALF - Alcalinitation $40 \%$.
\end{abstract}

\section{INTRODUCTION}

Composite material to be an alternative material beside metals, ceramics, and polimers, Composite materials is a fusion of some materials, that had a different chemical properties and physical, so that had a new mechanical properties from source materials, the reinforce of composite usually fiberglass or fiber carbon. Application composit for alternatif materials beside metals or another materials has been done in various aspect, for example in automotive , application of composite materials for automotive industry are doorpanel, roof cover, dashboard and leather at car seat, and that useing a synthetic fiber such as fiberglass or fiber carbon. Composite reinforced synthetic fiber had some disadvantage, specially unfriendly with nature, difficult decomopsed, and unfriendly with our body (Engineering360, n.d.). So that synthetic fiber should be replace by natural fiber. Natural fiber had more advantages, because its cheaper, more healty, and could be renewable . In 1999, Bledski and Gassan investigated natural fiber as a reinforced plastic, and 2008, development in automotive aspect starts from 2008 by John, in his study, he developt natural fiber composite for aplication cover door panel, and roof cover (Panyasart, Chaiyut, Amornsakchai, \& Santawitee, 2014). One of natural fiber can use is pineapple leaf fiber (PALF), it has good mechanical properties, tnesile strength 126MPa, modulus young 4405 Mpa (BPS Kaltim, 2015). In Borneo,production of pineapple good enough, that reached 25.344 ton in 2014, its means more leaves became waste (Kengkhetkit \& Amornsakchai, 2012). Pineapple Leaf Fiber (PALF) contain 70-80 \% celullose. Thus cellulose had a crystalline structure, so mechanical properties of PALF were good (Devi, Bhagawan, \& Thomas, 1997). Cellulose must be separated from another contain of fiber with some chemical treatment, such as alkaline treatment, and bleaching treatment. Alkaline treatment were using $\mathrm{NaOH}$ solution to eliminated hemicellulose and wax, and bleaching treatment using $\mathrm{NaClO}_{2}$ to eliminated Lignin and some hemicellulose(Asim, Jawaid, Abdan, \& Ishak, 2016).

Some study about PALF composite were promising in recent years, especially as a composite matrix polimer. Shih YF et.al. in 2012 using PALF with Polybutilane succianate as a matrix, and Polyprophylane as a matrix was investigated in same year, in 2008, Wang KH study about PALF composit with Poly(lactidacid) as a matrix and 
many more (Shih et al., 2014). In this study, experimental investigation were performed to determined the effect of chemical treatment on the mechanical properties of PALF composite with polyester matrix.

\section{MATERIALS AND METHODS}

\section{Preparation of PALF}

Pineapple leaf was found at Balikpapan KM 32nd, that leaves separate from the fiber. The fiber was dried at outside to decreasing moisture from fiber. Next step pineapple leaf fiber (PALF) was cut of $5 \mathrm{~mm}$ and ready to use. The inggredients of Pineapple Leaf Fiber at table below.

Table 1 : Inggredients of Pineapple Leaf Fiber

\begin{tabular}{ll}
\hline Composition & $\mathbf{\%}$ \\
\hline Cellulose & $69,5-79,5$ \\
Pentose & $17-17,8$ \\
Lignin & $4-4,7$ \\
Pectin & $1-1,2$ \\
(protein, organic acid ,wax dll) & Balance \\
\hline
\end{tabular}

\section{Alkaline Treatment}

Pineapple Leaf Fiber (PALF) from the previous preparation were immerge and stirred continously in 10\% $\mathrm{NaOH}$ solution at temperature $70^{\circ} \mathrm{C}$ for 4 hour. The weight ratio of $\mathrm{NaOH}$ solution per fiber was fixed at 20:1. Next the PALF was neutralized by aquadest until pH 7-8, and dried it at room temperatur for $24 \mathrm{~h}$.

\section{Bleaching}

Alkalinized Pineapple Leaf Fiber (PALF) from the alkaline treatment were immerge and stirred continously in $\mathrm{NaClO}_{2} 1.7 \% \mathrm{CH}_{3} \mathrm{COOH} 0,2 \mathrm{M}$ as a buffer solution at temperature $80^{\circ} \mathrm{C}$ for 4 hour. The weight ratio of $\mathrm{NaClO}_{2}$ 1.7\% solution per fiber was fixed at 20:1. Next the PALF was neutralized by aquadest until pH 7-8, and dried it at room temperatur for $24 \mathrm{~h}$.

\section{Composite Manufacturing}

Three PALF i.e. untreated, alkaline treated, and bleaching treated, were dried before use. Tensile spesimen ASTM D 638 was molded by hand lay up method and the orientation of fiber was random short fiber composite. The variation of volume fraction was obtained, there was $20 \%, 30 \%$ and $40 \%$ for untreated, alkaline treated, and bleaching treated.

\section{Tensile Strength}

Tensile strength were determined with universal testing maching (SHIDMADZU) at Airlangga University, Surabaya. Tensile testing carried out following ASTM D 638 respectively. The mean value at least 3 speciment is repost for each property.

\section{Morphology, Dispersion and Distribution of Fiber}

Fractured surface were observed under an optical microscope PrimoStar, with total magnification is 63x. Morevoer, fractured surface wer observed under DSLR Camera with macro lens to obtained dispersion and distribution of fiber at composite. 


\section{RESULT AND DISCUSSION}

\section{Alkaline Treatment of PALF}

Alkaline Treatment has been done to decrease wax and hemicelulose in pineapple leaf fibre in Fig. 1. These component were disadvantageous, becous it can made bond of fiber and matrix weaken. In this precess, wax and hemicelullose were dissolved with $\mathrm{NaOH}$, so the contain of celullose was actualy increase. Alkaline treatment can increase wettability and interface bonding between matrix and fiber grow up.

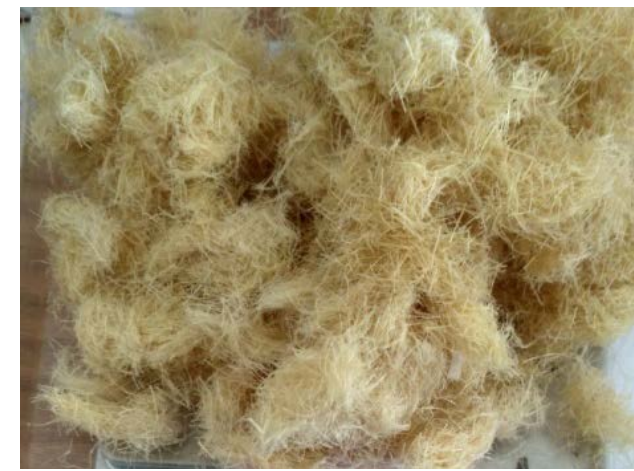

FIGURE 1. PALF after Alkaline Treatment

\section{Bleaching Treatment of PALF}

After alkaline tratment, next process was bleaching tratment, the purpose of bleaching tratment to degrade lignin and hemicelullose in pineapple leaf fiber (PALF), so the cellulose content was increase. Cellulose had good mechanical properties and Crystalline, and it can effect increasing mechanical properties of composite.

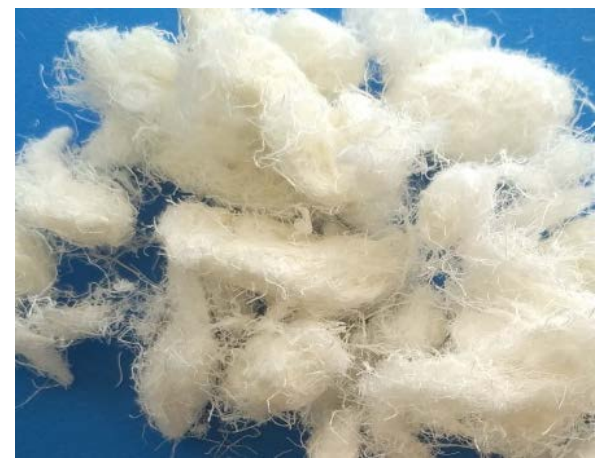

FIGURE 2. PALF After bleaching treatment

\section{Composite ManufacturingProcess}

The short fiber composite were prepared with hand lay up method, and room temperatur. Composite were prepared following standard of specimen ASTM D 638 in Figure 3, every variation of this study were prepared 3 specimen. 

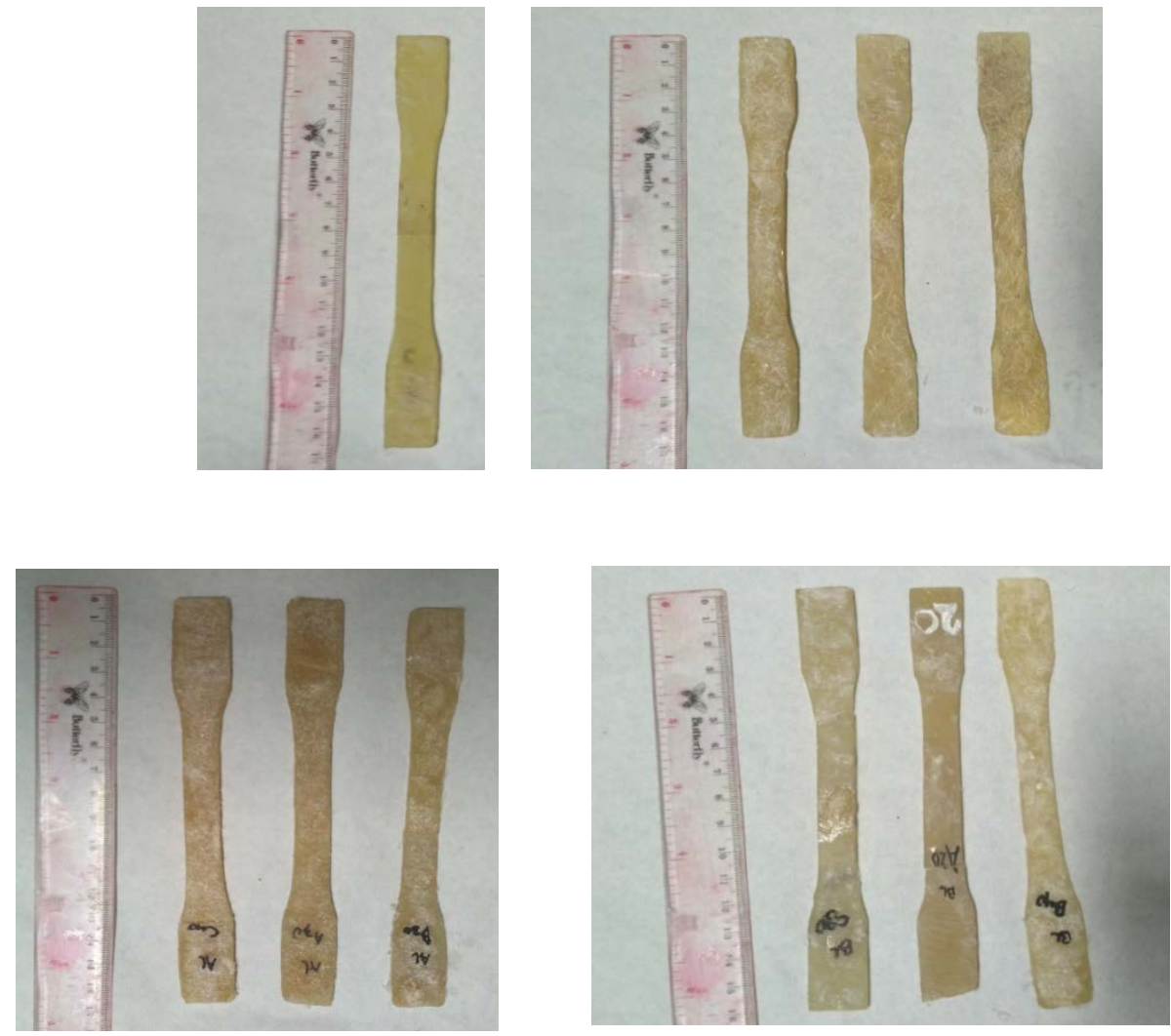

FIGURE 3. Tensile test specimen D 638 with Hand Lay Up Method

\section{Tensile Properties of Composite}

Tensile testing was observed to know ultimate tensile strength of composite with reinforced untreated PALF, alkaline trated PALF, and Bleached PALF. Tensiletes was observed at Laboratory Clinical Pharmacy, Airlangga University, Surabaya.

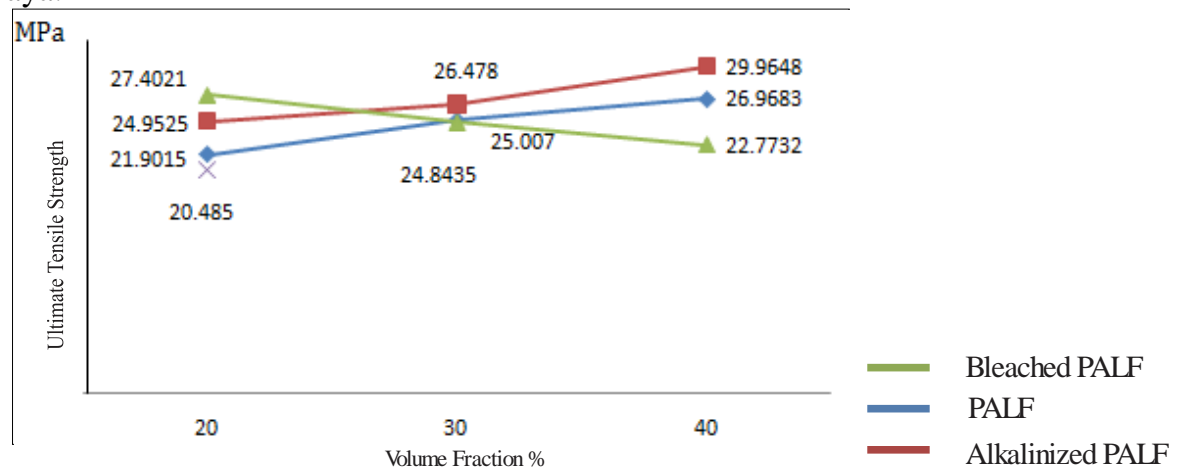

FIGURE 4. Ulltimate Tensile Strength of composite

In Figure 4, there had an increasing value of ultimate tensile strength for composite with untreated PALF, and alkaline treated PALF following addition of volume fraction of fiber. However, there is degradation of ultimate tensile strength of bleached treated PALF following addition of volume fraction of fiber. All value ultimate tensile strength of composite reinforced PALF were higher than neat poliester, and the value of alkaline treated PALF were 
higher than untreated PALF. And bleached treated PALF value were higher thanalkaline treated PALF and untreated PALF at $20 \%$ volume fraction.

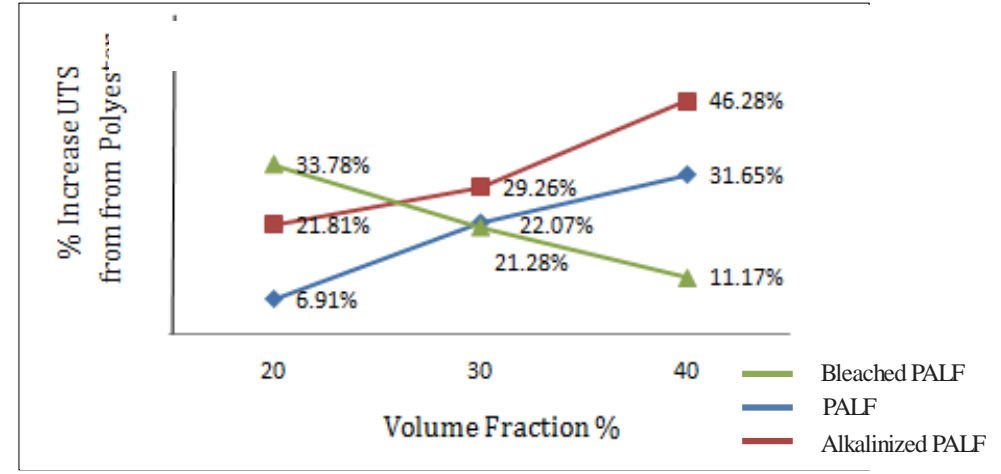

FIGURE 5. Percentage of increasing Ultimate Tensile Strength

So, PALF treatment had some effect for mechanical properties of composite reinforced PALF, different treatment had different effect of mechanical properties. The best treatment determined Figure 5 were bleaching treatment for volume fraction 20\%. However, the optimum value were alkaline treated PALF with volume fraction $40 \%$. The chemical treatment verified that can improve mechanical properties, degradation of hemicellulose and lignin had improve the content of cellulose, and respectively, mechanical properties of composite were increase. Degradation of wax layer and hemicellulose were these component hidrophobic able to improve wettability and bonding between fiber and matrix better, so mechancal properties were increase.

\section{Dispersion and Distribution Effects}

Dispersion and distribution of fiber at composite were very important, because that can influence mechanical properties of composite. If distribution and dispersion were good, mechanical properties would improve.

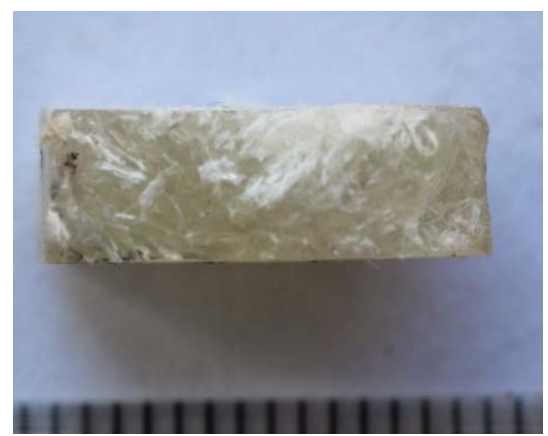

(a)

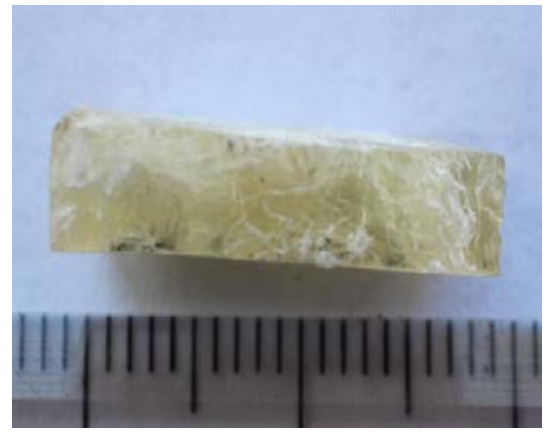

(c)

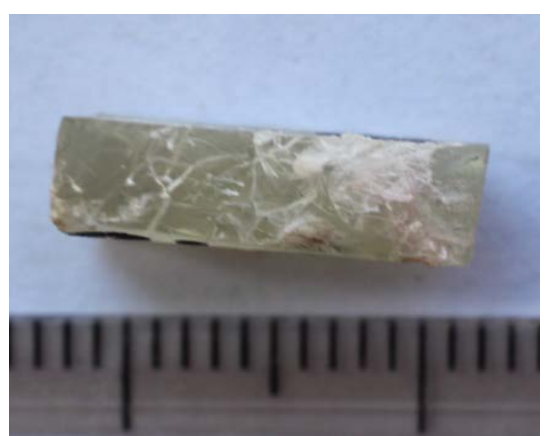

(b)

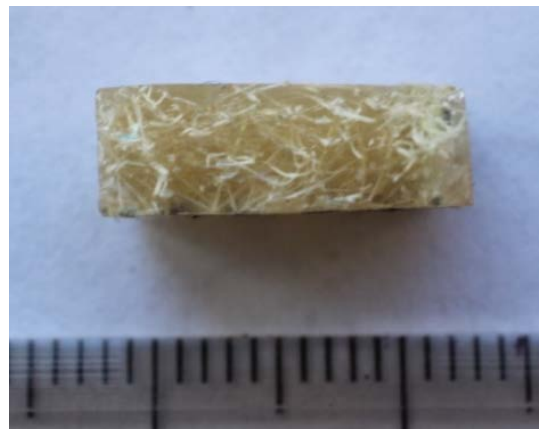

(d) 


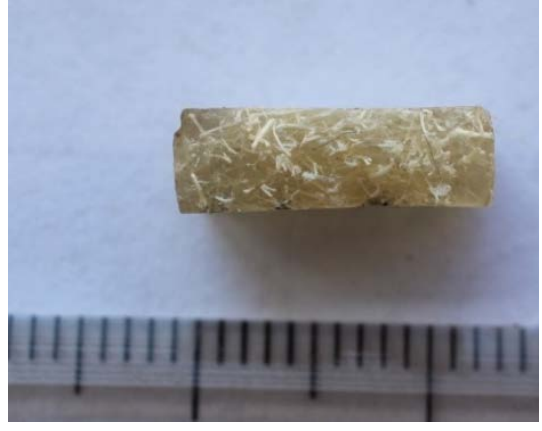

(e)

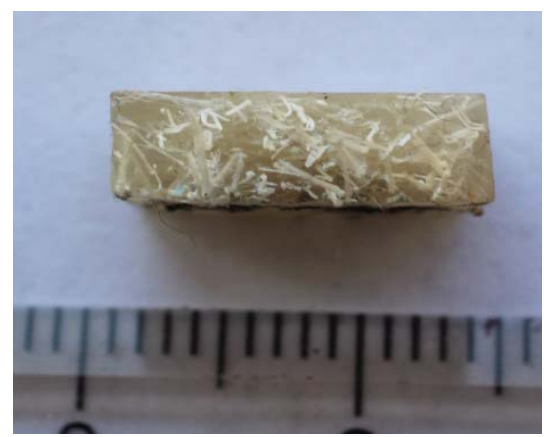

(g)

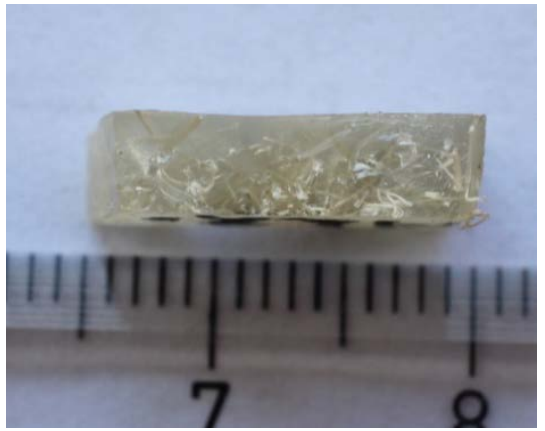

(f)

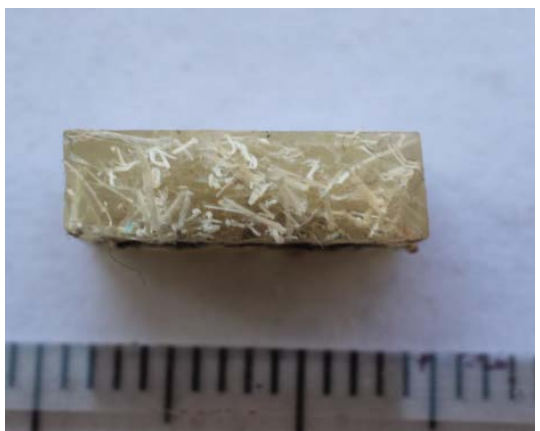

(h)

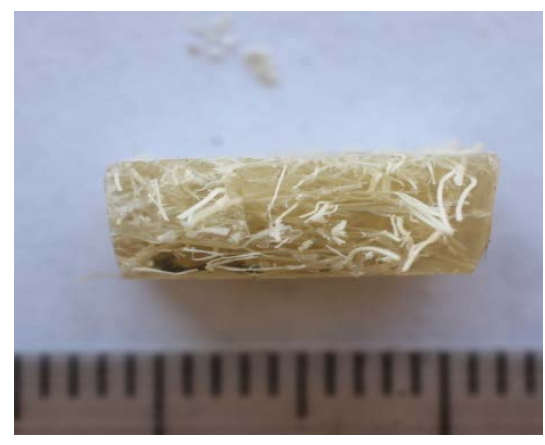

(i)

FIGURE 6. Fractured surface a) bleached PALF $40 \%$; b) bleached PALF $30 \%$;c) bleached PALF 20\% ; d) Alkalinized PALF $40 \%$; e) Alkalinized PALF30\% ; f) Alkalinized PALF 20\%; g) PALF 40\% ; h) PALF 30\% ; i) PALF 20\%

In Figure 6. observed there were photo of fracture surface after tensile test, in Figure 6.a and b, its clearly that distribution and dispersion of fiber were not good, an agglomeration found in bleached PALF 40\% and 30\% composite, that indicated poor distribution and dispersion. So, mechanichal properties decreased, it shown in figure 4, ultimate tensile strength of $30 \%$ and $40 \%$ bleached PALF composite respectively decreased. Panyasart et.al investigated distribution and dispersion of composite would decreased mechanical properties, because the matrix can't cover all of fiber, so distribution of stress when sample received loading weren't good enough, and mechanical properties were slightly decreased. 


\section{Morphology of Composite}

In Figure. 7 it shown morphology observed under optical microscope, Figure 7.a and b, its clearly shown that fiber pull out were obtained in composite bleached PALF 30\% and 40\%, that's indicated compatibility of fiber of composite weren't good, matrix couldn't binding fiber perfectly. So, mechanical properties has more lower than other. Manalo et.al investigated ${ }^{[14]}$ fiber pull out indicated low wettability of fiber, so binding between matrix and fiber weren’t going well, and caused matrix broke before fiber received a load.

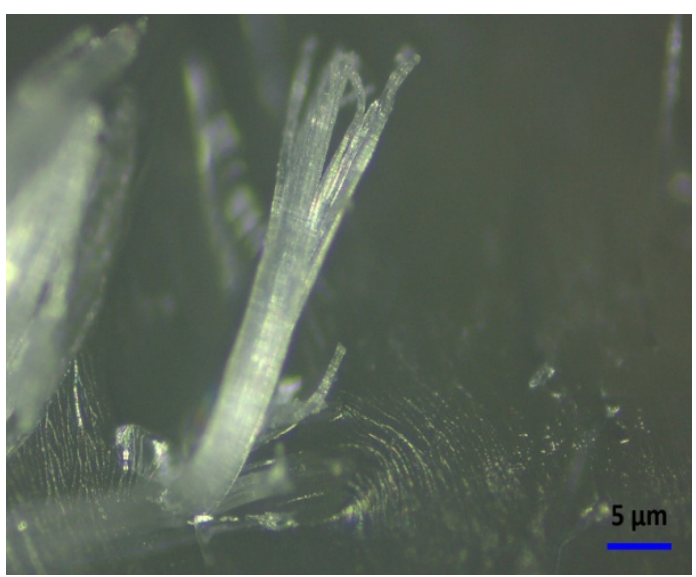

(a)

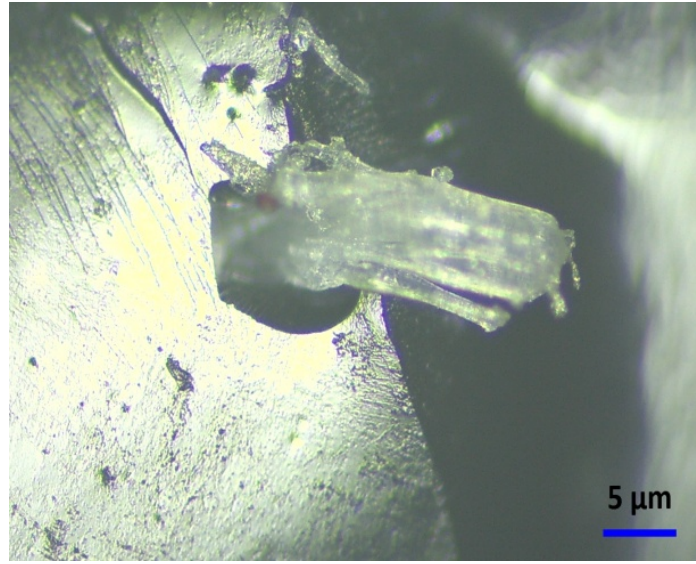

(b)

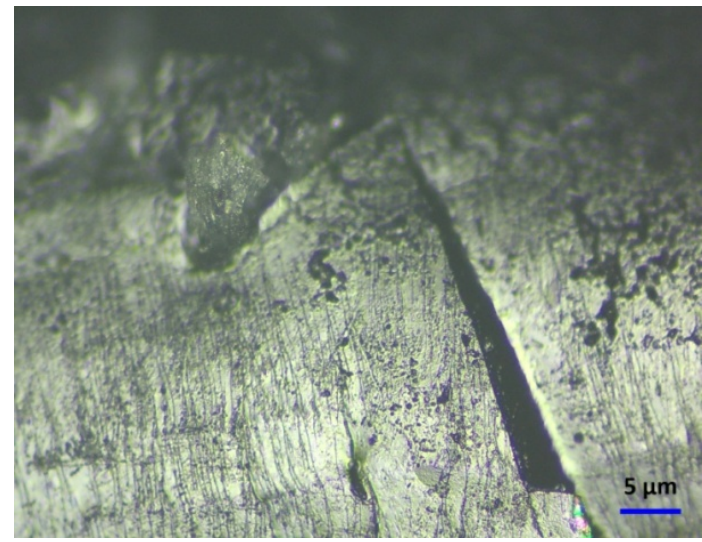

(c)

FIGURE 7. Morphology of fractured surface composite; a) Bleached PALF 40\%; Bleached PALF 30\%; c) Bleached PALF 20\%

\section{CONCLUSION}

Ultimate Tensile Strength value increased following increasing volume fraction of fiber, except Bleaced PALF, the optimum value of Ultimate Tensile Strength is 29.9648 MPa for $40 \%$ Alkalinized PALF composite. Dispersion and Distribution was discovered, there is an agglomeration at composite bleached PALF $30 \%$ and $40 \%$, so Ultimate Tensile Strength decreased at 30\% and 40\% Bleached PALF. Morphology of composite was discovered and found fiber pull out at bleached PALF composite $30 \%$ and $40 \%$

\section{ACKNOWLEDGMENTS}

We thank to Prof. Sulistijono, DEA for his assistance and comments that improved greatly the manuscript. 


\section{REFERENCES}

Asim, M., Jawaid, M., Abdan, K., \& Ishak, M. R. (2016). Effect of Alkali and Silane Treatments on Mechanical and Fibre-matrix Bond Strength of Kenaf and Pineapple Leaf Fibres. Journal of Bionic Engineering, 13(3), 426435. https://doi.org/10.1016/S1672-6529(16)60315-3

BPS Kaltim. (2015). Tabel Statis.

Devi, L. U., Bhagawan, S. S., \& Thomas, S. (1997). Mechanical properties of pineapple leaf fiber-reinforced polyester composites. Journal of Applied Polymer Science, 64(9), 1739-1748. https://doi.org/10.1002/(SICI)1097-4628(19970531)64:9<1739::AID-APP10>3.0.CO;2-T

Engineering360. (n.d.). Synthetic Fibers and Fabrics Information. Retrieved October 21, 2016, from https://www.globalspec.com/learnmore/materials_chemicals_adhesives/composites_textiles_reinforcements/s ynthetic_fibers_fabrics_polymer_textiles

Kengkhetkit, N., \& Amornsakchai, T. (2012). Utilisation of pineapple leaf waste for plastic reinforcement: 1. A novel extraction method for short pineapple leaf fiber. Industrial Crops and Products, 40, 55-61. https://doi.org/10.1016/J.INDCROP.2012.02.037

Panyasart, K., Chaiyut, N., Amornsakchai, T., \& Santawitee, O. (2014). Effect of Surface Treatment on the Properties of Pineapple Leaf Fibers Reinforced Polyamide 6 Composites. Energy Procedia, 56, 406-413. https://doi.org/10.1016/J.EGYPRO.2014.07.173

Shih, Y.-F., Chang, W.-C., Liu, W.-C., Lee, C.-C., Kuan, C.-S., \& Yu, Y.-H. (2014). Pineapple leaf/recycled disposable chopstick hybrid fiber-reinforced biodegradable composites. Journal of the Taiwan Institute of Chemical Engineers, 45(4), 2039-2046. https://doi.org/10.1016/J.JTICE.2014.02.015 